M.L. Dekhtyar ${ }^{1}$, V.M. Rozenbaum ${ }^{2}$, N.G. Shkoda ${ }^{2}$, M.I. Ikim ${ }^{3}$

\title{
RATCHET EFFECT IN BROWNIAN PHOTOMOTORS: SYMMETRY CONSTRAINTS AND GOING BEYOND THEM
}

\author{
${ }^{I}$ Institute of Organic Chemistry of National Academy of Sciences of Ukraine \\ 5 Murmanska Str., Kyiv,02094,Ukraine,E-mail: mdekh@mail.ru \\ ${ }^{2}$ Chuiko Institute of Surface Chemistry of National Academy of Sciences of Ukraine \\ 17 General Naumov Str., Kyiv,03164,Ukraine,E-mail:vik-roz@mail.ru \\ ${ }^{3}$ Semenov Federal Research Center for Chemical Physics RAS \\ 4 Kosygina Str., Moscow, 119991, Russian Federation
}

The symmetry conditions have been derived for the occurrence of the ratchet effect in Brownian photomotors. To this end, spatiotemporal symmetry operations in vector transformations, coordinate and time shifts, and in the overdamped regime were applied to the average photomotor velocity taken as a functional of the coordinate- and time-dependent potential energy. As established, individual Brownian particles (molecules) can move directionally only provided a symmetrically distributed charge fluctuates in them and they are placed on the substrates with an antisymmetric charge distribution or, vice versa, they are characterized by antisymmetrically distributed charge fluctuations and are placed on symmetric substrates. The collective directed motion of orientation-averaged particles is possible only in the former case. If a particle charge distribution is described by a time dependence with the universal type of symmetry (i.e., simultaneously symmetric, antisymmetric, and shift-symmetric), an additional symmetry constraint on the ratchet functioning arises: the ratchet effect is ruled out in the overdamped regime but allowed for inertial moving particles if the charge distributions in both the particle and the substrate are neither symmetric nor antisymmetric.

The effect of the universal type of symmetry is exemplified by dipole photomotors derived from donor-acceptor conjugated organic molecules. With a specific type of molecular photoexcitation and a specific relationship of the dipole moments in the ground and excited states, the ratchet effect becomes symmetry-forbidden. The forbiddenness can be removed by molecular polarization effects, which in this case become the predominant factor governing the direction of the motion and average velocity of photomotors. The estimated velocities of polarization photomotors are an order of magnitude larger than for known motor proteins and dipole Brownian photomotors. These results can be helpful in the purposeful molecular design of dipole photomotors.

Keywords: molecular devices, ratchet effect in Brownian photomotors, symmetry constraint, donor-acceptor systems, polarization effects

\section{INTRODUCTION}

Early studies on molecular machines, in particular, Brownian motors (ratchets), go back to more than 60 years ago [1-3] and since then remarkable progress has been achieved in mimicking and harnessing natural nanodevices as well as in constructing their human-made counterparts [4-9], which is essentially due to the rationalization and theoretical modelling of their working processes [10-16]. The necessary conditions for a Brownian motor to operate, i.e., for a particle (molecule) to execute directed motion, are as follows. There should exist at least two alternating states, with the potential energy of the particle being spatially asymmetric at least in one of them. Such devices can be classified according to how their states are interswitched: thermally, electrically, chemically, by light excitation, etc. If light is used as a switch, they are referred to as Brownian photomotors and it is feasible to control their properties by the exciting laser pulses.

Basically, Brownian photomotors represent nanosized ratchets that transform nonequilibrium fluctuations into directed motion at the expense of the energy of resonant laser radiation [17]. To exemplify, a large molecule or nanoparticle with a certain electron density (charge) distribution is positioned over a substrate generating a periodic (along the surface) electrostatic field. This field, together with near-surface repulsive forces, gives rise to a surface-normal potential holding the particle over the surface at a certain distance. On the other hand, the surface-parallel component of the electric field interacts with the particle 
electron density in the subthermal energy range thus allowing the particle to move Brownianly along the surface. When irradiated with laser pulses resonant with its first electron transition, the particle is excited and the overall workability of the nanodevice depends on the excitation/deexcitation timescales which, in turn, are governed by the laser pulsing mode. Indeed, the corresponding Brownian photomotor can operate only provided the laser intensity is sufficiently strong and the time intervals with the laser turned on or off are long enough to enable electron excitation during a laser pulse and its return to the ground state, in parallel with the particle diffusion over a sufficient distance (comparable to the period of the potential profile), between pulses. With these conditions satisfied, the potential energy of the particle depends not only on its spatial position, but also on time, which is a necessary condition for the ratchet effect and, hence, for the operation of a Brownian photomotor.

Further necessary conditions for the photomotor to function follow from the symmetry analysis of the spatial symmetry of the system and the time symmetry of fluctuations. As a simple example, it is intuitively clear that systems with mirror symmetry (i.e., with the same conditions for motion to the left and right) rule out the ratchet effect so that the average velocity of directed motion in them should be zero. For a more detailed symmetry analysis, it is necessary to know the dependence of the average motor velocity on the potential energy in an explicit form and to take into account the spatiotemporal symmetry of the potential energy. With this knowledge, consideration can include interacting charge distributions in the particle and the substrate which are determined by the time dependences of fluctuations.

Some symmetry properties of the Brownian photomotors were thus investigated in the overdamped regime (when friction predominates over inertia and the motion of a Brownian particle obeys the Smoluchowski equation [12]) and in the high-temperature approximation (when the potential energy of the system is low compared to the thermal energy $k_{B} T$, where $k_{B}$ is the Boltzmann constant and $T$ is the absolute temperature) affording simple analytical relations for the average motor velocity $[18,19]$. However, they were restricted to stochastic dichotomous fluctuations of potential energy, whereas deterministic fluctuations appear to be more important for photomotor operation, in accord with the deterministic nature of laser pulse cycles [20].

It is also to be borne in mind that the charge distributions in the substrate and the particle respond to laser turning-on and off not instantaneously but relaxationally, i.e., with a delay; as a result, the corresponding fluctuations cannot be regarded as dichotomous processes and the time dependence of the potential energy of the system should be described by a certain periodic function (arbitrary in the general case).

To meet these challenges, here we invoke another formalism of symmetry analysis, which provides much greater generality [21-25]. In terms of symmetry transformations under which the average photomotor velocity is invariant (up to a sign) and representing it as a functional of the potential energy, we derive essential symmetry exclusion rules for Brownian photomotors. They account for all previously considered specific cases [26]. We also address the situations, in which the symmetry forbiddenness of the ratchet effect is removed due to the interplay of a specific type of laser irradiation of molecules and specific characteristics of the compounds used in photomotors. Finally, the present study is aimed to demonstrate that symmetry analysis greatly adds to our understanding of the workability and design principles of Brownian photomotors.

\section{RESULTS AND DISCUSSION OPERATIONS OF SPATIOTEMPORAL SYMMETRY IN BROWNIAN PHOTOMOTORS}

We consider the average velocity of directed motion of a particle $v=v\{V(x, t)\}$ as a functional of its potential energy $V(x, t)$, which is a periodic function of the spatial coordinate and time. The functional possesses the vector and shift symmetries, the former causing a sign reversal of all vector quantities under coordinate inversion and the latter making the functional invariant under a shift of the origin of coordinates by $x_{0}$ and a shift of the origin of time by $t_{0}$ :

$$
\begin{aligned}
& v\{V(-x, t)\} \underset{\text { (vect) }}{=}-v\{V(x, t)\}, \\
& v\left\{V\left(x+x_{0}, t+t_{0}\right)\right\} \underset{\text { (shift) }}{=} v\{V(x, t)\} .
\end{aligned}
$$


An interesting additional property, so-called hidden symmetry [22], emerges in the overdamped regime owing to a certain symmetry of the solutions of the Smoluchowski equation provided it includes the spatiotemporally periodic function $V(x, t)$ in which the coordinate and time arguments reverse sign simultaneously:

$v\{V(-x,-t)\} \underset{\text { (o-d) }}{=} v\{-V(x, t)\}$.

A straightforward proof of this relation is given in Refs. 19, 20. In eqns (1) and (2), and from now on, the subscripts (vect), (shift), and (o-d) below the equality signs denote the symmetry operations in vector transformations, coordinate and time shifts, and in the overdamped regime, respectively.

If a particle with the charge density distribution $p\left(x^{\prime}, t\right)$ is placed in the electrostatic field of a substrate with the potential $\varphi(x)$, the particle potential energy is expressed as

$$
V(x, t)=\int p\left(x^{\prime}, t\right) \varphi\left(x+x^{\prime}\right) d x^{\prime}
$$

(the integration is performed over all internal points of the particle). If the potential represents an antisymmetric $(N=1)$ or symmetric $(N=2)$ function, $\varphi(x)=(-1)^{N} \varphi\left(-x+2 x_{0}\right) \quad\left(x_{0} \quad\right.$ is the coordinate of the centre or axis of symmetry), and the charge density distribution is also described by an antisymmetric $(n=1)$ or symmetric $(n=2)$ function, $p\left(-x^{\prime}, t\right)=(-1)^{n} p\left(x^{\prime}, t\right)$ $\left(x^{\prime}\right.$ is reckoned from the centre of the particle considered), then the potential energy satisfies the following property of symmetry:

$$
V(x, t)=(-1)^{n+N} V\left(-x+2 x_{0}, t\right) .
$$

Thus, depending on the parity of the sum $n+N$, the potential energy belongs to antisymmetric (odd $n+N$ ) or symmetric (even $n+N)$ spatially periodic functions. Then symmetry transformations (1) yield the chain of equalities:

$$
\begin{aligned}
& v\{V(x, t)\}=v\left\{(-1)^{n+N} V\left(-x+2 x_{0}, t\right)\right\} \underset{\text { (shift) }}{=} \\
& \underset{\text { (shift) }}{=} v\left\{(-1)^{n+N} V(-x, t)\right\} \underset{\text { (vect) }}{=}-v\left\{(-1)^{n+N} V(x, t)\right\} .
\end{aligned}
$$

At even values of $n+N$, we obtain $v\{V(x, t)\}=-v\{V(x, t)\} \quad$ and, consequently, $v\{V(x, t)\}=0$, so that the ratchet effect does not exist for particles with a symmetric charge distribution on symmetric substrates $(n=N=2)$ or for particles with an antisymmetric charge distribution on antisymmetric substrates $(n=N=1)$. It can, therefore, be inferred that Brownian particles can move directionally only provided a symmetrically distributed charge fluctuates in them and they are placed on the substrates with an antisymmetric charge distribution or, vice versa, they are characterized by antisymmetrically distributed charge fluctuations and are placed on symmetric substrates.

Consider a particle with a reversed charge distribution, $\tilde{p}\left(x^{\prime}, t\right)=p\left(-x^{\prime}, t\right)$. The potential energy $\tilde{V}(x, t)$ of such particle is related to the initial potential energy $V(x, t)$ :

$\tilde{V}(x, t)=(-1)^{N} V\left(-x+2 x_{0}, t\right)$,

so that average velocities satisfy the following chain of equalities:

$$
\begin{aligned}
& v\{\tilde{V}(x, t)\}=v\left\{(-1)^{N} V\left(-x+2 x_{0}, t\right)\right\} \underset{\text { (shift) }}{=} \\
& \underset{\text { (shift) }}{=} v\left\{(-1)^{N} V(-x, t)\right\} \underset{\text { (vect) }}{=}-v\left\{(-1)^{N} V(x, t)\right\} .
\end{aligned}
$$

Introduce the average velocity of an ensemble of differently oriented particles:

$$
\langle v\rangle=\frac{1}{2}[v\{V(x, t)\}+v\{\tilde{V}(x, t)\}] .
$$

It follows from equalities (7) that this velocity is zero on symmetric substrates with $N=2$. The ensemble under consideration will spread with time as a result of non-zero average velocities of individual particles with an antisymmetric charge distribution.

Now consider the case when the particle charge distribution has the time dependence with the universal type of symmetry [23], which implicates, in particular, time antisymmetry $p\left(x^{\prime}, t\right)=-p\left(x^{\prime},-t+2 t_{0}\right)$. Then $V(x, t)=-V\left(x,-t+2 t_{0}\right)$, and the following chain of equalities holds:

$$
\begin{aligned}
& v\{V(x, t)\}=v\left\{-V\left(x,-t+2 t_{0}\right)\right\} \underset{\text { (shift) }}{=} \\
& \underset{\text { (shift) }}{=} v\{-V(x,-t)\} \underset{\text { (o-d) }}{=} v\{V(-x, t)\} \underset{\text { (vect) }}{=} \\
& \underset{\text { (vect) }}{=}-v\{V(x, t)\}=0 .
\end{aligned}
$$


It is thus evident that the ratchet effect is ruled out in the overdamped regime, irrespective of any charge distributions in the particle and the substrate.

The universal type of symmetry also includes shift symmetry (invariance, with a sign reversal, under a time half-period shift: $p\left(x^{\prime}, t+\tau / 2\right)=-p\left(x^{\prime}, t\right)$. As a result, the transformation

$v\{V(x, t)\}=v\{-V(x, t+\tau / 2)\} \underset{\text { (shift) }}{=} v\{-V(x, t)\}$

implies no time reversal and this equality is valid in the general case of inertial particles. According to equality (10), the functional is even with respect to the potential energy $V(x, t)$ and is not zero for an arbitrary spatial dependence of the function $V(x, t)$. On the other hand, if this spatial dependence is symmetric or antisymmetric, then, together with relation (10), the relation $v\{V(x, t)\}=-v\{-V(x, t)\}$ should hold thus suggesting the oddness of the same functional. If the functional is even and odd at the same time, it is equal to zero. The considered symmetry properties taken altogether lead to the inference that if the time dependence of the particle charge distribution is described by a periodic function of time with the universal type of symmetry, the ratchet effect is forbidden in the overdamped regime; beyond this regime, i.e., for inertial moving particles, the ratchet effect is allowed only provided the charge distributions both in the particle and in the substrate are neither symmetric nor antisymmetric.

\section{SYMMETRY IMPLICATIONS IN THE SEARCH FOR EFFICIENT PHOTOMOTOR MOLECULES}

To demonstrate the critical importance of symmetry analysis in the design of Brownian photomotors, we consider the motor applicability of molecules with their time-dependent charge distributions described by dipole moments $\mu(t)$. The potential energy $V(x, t)$ of a molecule (particle) with a dipole moment $\mu(t)$ and polarizability $\alpha$ moving in a stationary electric field $E(x)$, which is a periodic function along the $x$-coordinate, can be represented by the sum of the dipole and polarization energies:

$V(x, t)=-\mu(t) E(x)-\frac{1}{2} \alpha E^{2}(x)$.
Let the periodic function $\mu(t)$ with the period $\tau$ belong to the universal type of symmetry, $\mu(t) \equiv \mu_{u}(t)$, i.e., it is simultaneously symmetric, antisymmetric, and shiftsymmetric [23, 24] (for examples of such functions, see Fig. 1 below). It follows from Sec. II (see eqn (9)) that in the absence of polarization effects $(\alpha=0)$, the average photomotor velocity $v$ represented by a functional of the potential energy $v\{V(x, t)\}$ is zero, provided particles move without inertia in the overdamped regime. However, it can differ from zero for inertial particles if the function $E(x)$ is neither symmetric nor antisymmetric, i.e., does not represent the class of functions $E_{s, a}\left(x+x_{s, a}\right)= \pm E_{s, a}\left(-x+x_{s, a}\right)$, where the subscripts $s$ and $a$ denote, respectively, symmetric and antisymmetric functions with symmetry axes $x_{s}$ and centers of symmetry $x_{a}$, for which there is the upper or lower sign in the above relation. We now analyze the symmetry properties of the system with the polarization term in eqn (11) included. Since the function $\mu_{u}(t)$ is, in particular, shiftsymmetric, $\mu_{u}(t)=-\mu_{u}(t+\tau / 2)$, we arrive at the chain of equalities:

$$
\begin{aligned}
& v\{V(x, t)\}=v\left\{-\mu_{u}(t) E(x)-\frac{1}{2} \alpha E^{2}(x)\right\}= \\
& =v\left\{\mu_{u}(t+\tau / 2) E(x)-\frac{1}{2} \alpha E^{2}(x)\right\}= \\
& \text { (shift) } v\left\{\mu_{u}(t) E(x)-\frac{1}{2} \alpha E^{2}(x)\right\} .
\end{aligned}
$$

If we choose the function $E(x)$ to be antisymmetric, $E\left(x+x_{0}\right)=-E\left(-x+x_{0}\right)$, then we obtain:

$$
\begin{aligned}
& v\{V(x, t)\} \underset{\text { (shift) }}{=} v\left\{-\mu_{u}(t) E\left(x+x_{0}\right)-\frac{1}{2} \alpha E^{2}\left(x+x_{0}\right)\right\}= \\
& =v\left\{\mu_{u}(t) E\left(-x+x_{0}\right)-\frac{1}{2} \alpha E^{2}\left(-x+x_{0}\right)\right\}= \\
& \underset{\text { (shift) }}{=} v\left\{\mu_{u}(t) E(-x)-\frac{1}{2} \alpha E^{2}(-x)\right\}=\underset{\text { (vect) }}{=} \\
& \underset{\text { vect) }}{=}-v\left\{\mu_{u}(t) E(x)-\frac{1}{2} \alpha E^{2}(x)\right\} .
\end{aligned}
$$


Equating expressions (12) and (13) yields $v\{V(x, t)\}=0$, i.e., the ratchet effect is absent even with the non-zero polarization term, if the time dependence of the dipole moment belongs to the universal type of symmetry and the spatial dependence of the electric field strength is described by an antisymmetric periodic function. It is notable that this property is proved without using the time reversal operation and holds, therefore, for inertial particles as well. At $\alpha=0$, it is naturally reduced to the analogous property proved in Sec. II.

Let us examine electric fields

$$
E(x)=E_{0}+E\left[\sin \left(\frac{2 \pi x}{L}\right)+\frac{1}{4} \sin \left(\frac{4 \pi x}{L}\right)\right],
$$

which are presented as a sum of the constant contribution $E_{0}$ and the antisymmetric contribution, which, in turn, is the sum of two sinusoids with the amplitude $E$ and the spatial period $L$. When $E_{0}=0, E(x)$ is an antisymmetric function and there is no ratchet effect in this case even with polarization effects included $(\alpha \neq 0)$. Thus polarization effects can make the ratchet effect possible only if $E_{0} \neq 0$. For completeness, it should be noted that if $E(x)$ is a symmetric function, then the ratchet effect is totally ruled out at any spatial or time symmetries of the parameters of the model.

A time dependence with the universal type of symmetry can be exemplified by a symmetric dichotomic process (see Fig. $1 b$ ) for which the durations of the states with the laser turned on $\left(\tau_{+}\right)$and off $\left(\tau_{-}\right)$are equal and pulse intensity is sufficient to minimize relaxation processes [20]. With these conditions satisfied and the dipole approximation used, one can consider the dipole moments in the states with the laser turned on $\left(\mu_{+}\right)$and off $\left(\mu_{-}\right)$to be equal in magnitude and opposite in sign: $\mu_{+}=\mu_{-}$. We will follow a previously developed approach in the hightemperature approximation [27] to describe the dependence of the average photomotor velocity on the parameters of the model used.
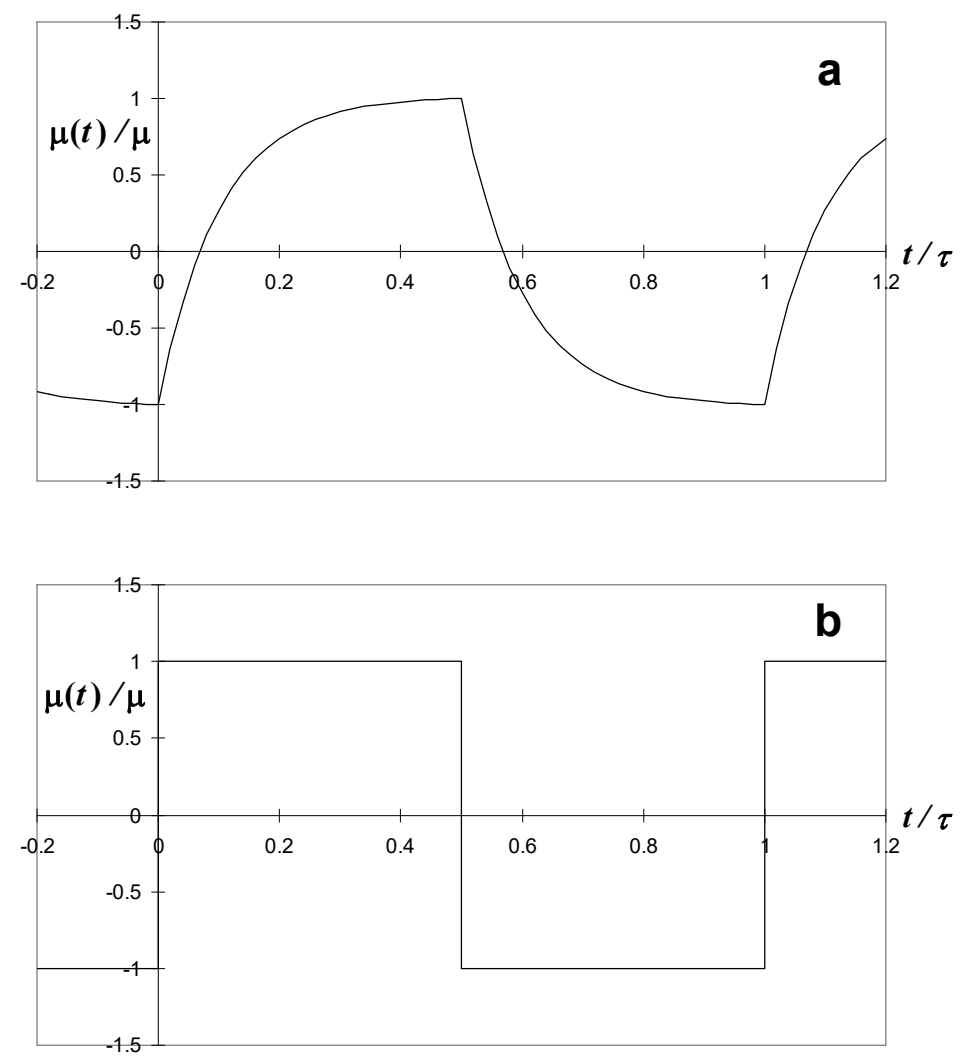

Fig. 1. Examples of the time dependences of the dipole moments which are periodic functions of universal symmetry: (a) relaxation adjustment of the electron level occupancies to periodic laser pulses, whose duration is equal to the time interval between them $\left(\tau_{+}=\tau_{-}\right)$and $(b)$ symmetric dichotomic process with instantaneous adjustment of two alternating states to the laser pulses 
As far as molecular dipole moments as indices of charge distributions are concerned, we examine dipole photomotors [17]. In this context, the significant parameters of a molecule are its dipole moments in the ground $\left(\mu_{0}\right)$ and excited electronic states $\left(\mu_{1}\right)$, and polarizability $\alpha$. The values of these parameters for several donoracceptor conjugated organic molecules including benzimidazole-pyridine betaines 1-3 [28, 29], ester-substituted aryl pyrene 4 , and stilbenoid zwitterionic merocyanine 5 are given in Table 1 .
These compounds were selected for the study, in addition to those previously discussed [30], due to the fact that on excitation, their dipole moments are dramatically changed in magnitude and sometimes invert the direction. This property, together with high polarizability of such molecules, makes them conspicuous examples of how polarization affects operation of dipole photomotors depending on symmetry factors.

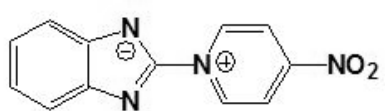

1

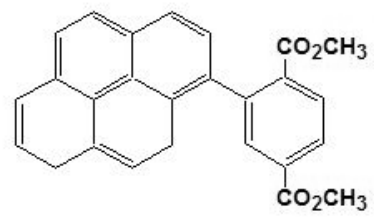

4

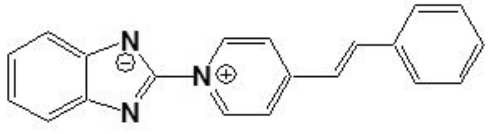

2

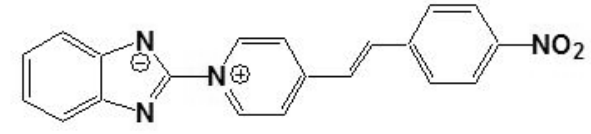

3

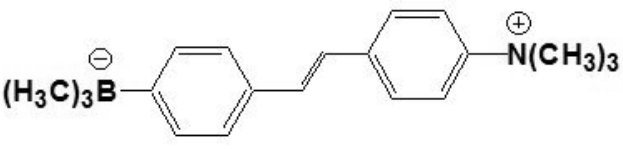

5

Table 1. Polarizability $\alpha$, dipole moments in the ground $\left(\mu_{0}\right)$ and first excited electronic states $\left(\mu_{1}\right)$, their difference $\Delta \mu=\mu_{1}-\mu_{0}$, discrepancy $\delta \mu=\left(3 \mu_{0}+\mu_{1}\right) / 4$, and factor $\delta \mu-\alpha E_{0}$ for organic molecules $1-5$ (calculated by the AM1 method using the AMPAC package [31])

\begin{tabular}{ccccccc}
\hline Compound & $\boldsymbol{\alpha}, \mathbf{A}^{\mathbf{3}}$ & $\boldsymbol{\mu}_{\mathbf{0}}, \mathbf{D}$ & $\boldsymbol{\mu}_{\mathbf{1}}, \mathbf{D}$ & $\boldsymbol{\Delta} \boldsymbol{\mu}, \mathbf{D}$ & $\boldsymbol{\delta} \boldsymbol{\mu}, \mathbf{D}$ & $\boldsymbol{\delta} \boldsymbol{\mu}-\boldsymbol{\alpha} \boldsymbol{E}_{\mathbf{0}}, \mathbf{D}$ \\
\hline 1 & 36.1 & 4.1 & -13.1 & -17.2 & -0.20 & -0.38 \\
2 & 46.3 & 10.8 & -3.2 & -14 & 7.30 & 7.07 \\
3 & 51.2 & 3.6 & -11.2 & -14.8 & -0.10 & -0.6 \\
4 & 40.9 & 2.4 & 26.8 & 24.4 & 8.50 & 8.30 \\
5 & 51.6 & 40.5 & 28.8 & -11.7 & 37.58 & 37.32 \\
\hline
\end{tabular}

When the laser is turned off, the molecule is in the ground state such that $\mu_{-}=\mu_{0}$. Induced by resonance laser emission, transitions between the ground and excited states occur, with their frequencies many orders of magnitude larger than the reciprocal state lifetimes, i.e., the reciprocal durations of laser pulses and the time intervals between them. If these durations are equal (a duty cycle of laser pulses is $50 \%$ ), and pulse intensity is sufficient to minimize relaxation processes [20], then we can assume the dipole moment in the state with the laser turned on to be the arithmetic mean of the dipole moments in the ground and excited states, $\mu_{+}=\left(\mu_{0}+\mu_{1}\right) / 2$ [20]. Expressing the condition $\mu_{+}=-\mu_{-}$in terms of $\mu_{0}$ and $\mu_{1}$, we arrive at the following condition for the forbiddenness of the ratchet effect in the overdamped regime:

$\mu_{1}=-3 \mu_{0}$

(with this relation between the ground- and excited-state dipole moments, potential energy (11) fluctuates in sign at $\alpha=0$ ).

Taking advantage of the previously derived expressions [20,27,30], we can conveniently express the average velocity of a photomotor 
governed by a symmetric dichotomic process $\left(\tau_{+}=\tau_{-}\right)$and placed in the electric field of strength (14) at $\left|\alpha E_{0}\right|<<\left|\mu_{0}\right|$ :

$$
v=\frac{\pi}{32} \frac{D}{L} \frac{\Delta \mu^{2} E^{3}}{\left(k_{B} T\right)^{3}} \Phi(\xi)\left(\delta \mu-\alpha E_{0}\right),
$$

where $D / L$ is a factor with the dimension of velocity ( $D$ is the diffusion coefficient),

$$
\Phi(\xi)=\frac{\xi(1+2 \xi)}{(1+\xi)(1+4 \xi)^{2}}
$$

is a nonmonotonic function of the frequency parameter $\zeta=(L / 2 \pi)^{2}(D \tau)^{-1}$ (with the laser cycle period $\tau=\tau_{+}+\tau_{-}, \tau_{+}=\tau_{-}$) assuming the maximum value $\Phi_{\max }(0.3388) \approx 0.2296$ [27], $\Delta \mu=\mu_{1}-\mu_{0}$ is the dipole moment difference, and $\delta \mu=\left(3 \mu_{0}+\mu_{1}\right) / 4$ is a discrepancy of dipole moments. In the case $\delta \mu=0$ (i.e., when eqn (15) holds), the ratchet effect is possible only provided that $\alpha \neq 0$ and $E_{0} \neq 0$. As seen, a stopping point emerges when $\delta \mu=\alpha E_{0}$ and, accordingly, the photomotor moves in opposite directions at $\alpha E_{0}<\delta \mu$ and at $\alpha E_{0}>\delta \mu$. It is also evident from eqn (16) that the average velocity is zero at $\Delta \mu=0$, i.e., at equal ground- and excited- state dipole moments, which is an expected forbiddenness for dipole photomotors.

The donor-acceptor conjugated organic compounds given in Table 1 exemplify various symmetry-induced peculiarities of the ratchet effect. Benzimidazole-pyridine betaines 1-3 are remarkable for the inversion of the dipole moment direction on electronic excitation. This rather rare feature typical, however, for this family of organic compounds was revealed by calculations [28] and solvatochromic analysis [29]. Indeed, pyridinium betaines have a dipole moment directed from the donor to the acceptor moiety in the ground state and vice versa in the excited state, in contrast to most of donoracceptor molecules, in which this vector is directed from the acceptor to the donor in the ground state and keeps its direction unchanged on excitation. For instance, compound 1 exhibits a complete shift of electron density from the pyridine to the benzimidazole moiety in the ground state while the first excited state is characterized by a pronounced reverse electron transfer (the shapes of the corresponding molecular orbitals involved in the first electronic transition are shown in Fig. $2 a$ ).

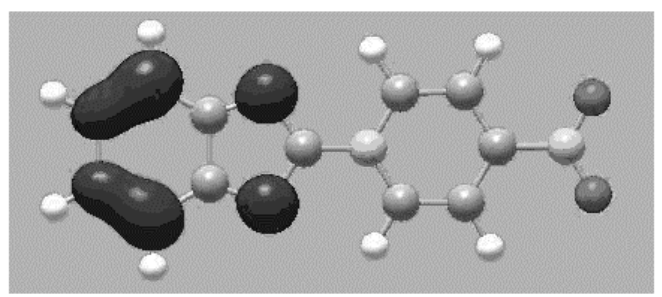

HOMO-1

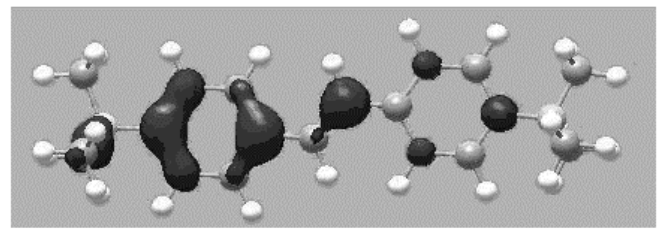

HOMO

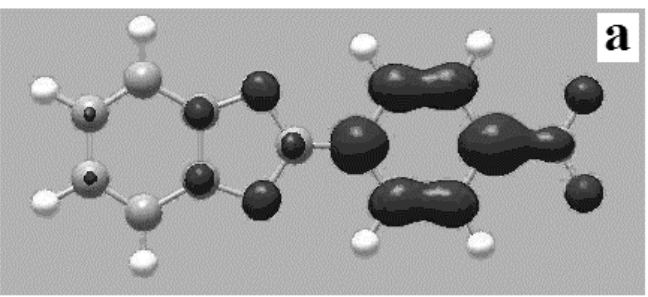

LUMO

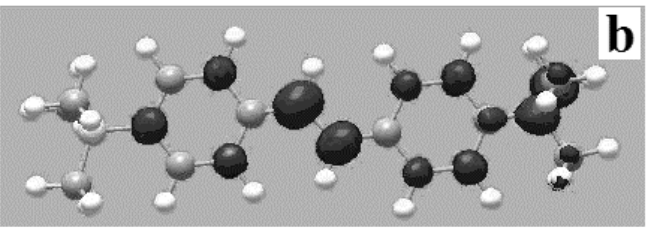

LUMO

Fig. 2. HOMO-1 and LUMO for $1(a)$, and HOMO and LUMO for $5(b)$ involved in their first singlet electronic transitions (here HOMO, HOMO-1, and LUMO designate the highest occupied, next-to-highest occupied, and lowest unoccupied molecular orbitals)

As a result of a significant change in the dipole moment on excitation, compounds $1-3$ do not only appear as promising nonlinear optical materials [28, 29], but are also expected to afford high velocities of the dipole photomotors [17].
However, as far as molecules 1 and 3 are concerned, their very applicability in Brownian ratchets is questionable because they both have rather close-to-zero dipole moment discrepancies $\delta \mu(0.2$ and $0.1 \mathrm{D}$, respectively), which provides 
almost exact satisfaction of eqn (15) thus making the ratchet effect symmetry-forbidden when $\alpha=0$. It is only due to the rather high polarizabilities of compounds 1 and 3, that they are nevertheless appropriate as photomotor particles, since the corresponding values of the factor $\left(\delta \mu-\alpha E_{0}\right)$ sufficiently differ from zero (see Table 1). Therefore, the ratchets derived from them can be called polarization photomotors. Contrary to its counterparts 1 and 3 , betaine 2 is beyond the region of symmetry forbiddenness, though also exhibiting the inversion of the dipole moment direction on excitation. This distinction follows from a too small ratio of the excited- to ground-state dipole moment absolute magnitudes, such that eqn (15) does not hold for compound 2. Importantly, compounds with small dipole moment discrepancies (like 1 and 3) prove very sensitive to the nature of the solvent, as their dipole moments of the ground and excited states can be tuned by the polarity of the medium; this effect should be taken into account in constructing photomotors and selecting liquid media for them.

Compounds 4 and 5 both have large values of $\Delta \mu$ but the former undergoes a more drastic change in the dipole moment on excitation. On the other hand, the latter molecule is noted for an outstandingly high dipole moment discrepancy (see Table 1). The interplay of the two factors is expected to provide much the same average velocities of the corresponding dipole photomotors, in accord with eqn (16). The dipole moment of these compounds does not change its direction on excitation. It is notable that zwitterionic molecule 5 behaves somewhat similar to betaines 1-3: the electron density is located predominantly on the donor moiety in the ground state (since the mesomeric electron withdrawal from the donor is precluded) such that the dipole moment is directed from the donor to the acceptor (see Fig. $2 b$ ). On excitation, the electron density significantly shifts towards the acceptor (thereby strongly reducing the magnitude of the dipole moment), but not to a sufficient degree for the dipole moment to change sign. The sign invariance of the dipole moments of compounds 4 and 5 gives rise to a definite advantage of the corresponding photomotors, namely, their "symmetry stability": large dipole moment discrepancies $\delta \mu$ prevent expression (16) from going to zero, i.e., rule out the symmetry forbiddenness of the ratchet effect irrespective of the medium in which motor molecules are placed.

The molecular parameters relevant to the desired ratchet effect as well as the average photomotor velocity can be estimated as follows. The characteristic values of the dipole energy of a photomotor $\mu_{0} E$ are usually about $10 \%$ of the thermal energy $k_{B} T$ at room temperature $T=300 \mathrm{~K}$ [17]. Then, with the characteristic values of dipole moments $\mu_{0} \sim 1 \mathrm{D}$, the electric field strength $E$ can reach $10^{6} \mathrm{~V} / \mathrm{cm}$, which corresponds in order of magnitude to the electric fields over the polar substrates at a distance of several angstroms from them. Substituting this value into $\alpha E_{0}$ with the characteristic value of polarizability $\alpha \sim 10 \AA^{3}$, we obtain $\alpha E_{0} / \mu_{0} \sim 0.05$. Thus, the induced dipole moment $\alpha E_{0}$ can compete with the dipole moment discrepancy $\delta \mu$ if $\delta \mu \approx 0.05 \mu_{0}$.

Starting from the above estimates and molecular parameters given in Table 1, we can calculate the factor $\delta \mu-\alpha E_{0}$ for molecules $1-5$ (taking account that $\alpha$ is always positive and $E_{0}$ can be selected positive). This factor is calculated to be negative for compounds 1 and 3 and positive for 2, 4, and 5; accordingly, the two groups of the corresponding photomotors, if placed under the same conditions, should move with significant velocities in opposite directions. It should be noted that the close-to-zero magnitudes of $\delta \mu-\alpha E_{0}$ found for 1 and 3 suggest, on the one hand, markedly reduced photomotor velocities but, on the other hand, easy mediumcontrol of stopping points and of the motion direction.

With the plausible approximate values of the model parameters, $D=10^{-9} \mathrm{~m}^{2} / \mathrm{s}$ and $L=5 \AA$, we obtain the dimensional factor $D / L=2 \mathrm{~m} / \mathrm{s}$ in eqn (16). Then the characteristic average velocity of the dipole photomotor at $\Delta \mu \sim \delta \mu \sim \mu_{0}$ is estimated as $0.1(D / L)\left(\mu_{0} E / k_{B} T\right)^{3} \Phi_{\max } \approx 50 \mu \mathrm{m} / \mathrm{s}$. As a comparison, the ratchet effect arising solely from the polarization contribution at $\delta \mu=0$ provides, due to the factor $\alpha E_{0} / \mu_{0} \sim 0.05$, the average velocity $v \approx 2.5 \mu \mathrm{m} / \mathrm{s}$, which is about an order of magnitude larger than the velocity of motor proteins (kinesins) $[17,32,33]$ and previously discussed photomotors [18-20]. Thus, the polarization photomotors, which function due to the removal of the symmetry constraint on the ratchet effect should have experimentally observable and practically valuable characteristics. 


\section{CONCLUSIONS}

Spatiotemporal symmetry operations applied to the average photomotor velocity in terms of the potential energy functional yielded the symmetry conditions for the occurrence of the ratchet effect of a Brownian photomotor, which essentially generalize the relationships found previously $[18,19,26]$ for high-temperature photomotors with dichotomous fluctuations of the potential energy. Analytical relations (5)-(8) enable the selection of photomotor systems (constituted by moving particles and stationary substrates) which would be free of symmetryinduced limitations on the motor operation. Symmetry forbiddenness can be avoided if charge distributions in two units of a given motor have different symmetries, i.e., symmetric in the motor particle (molecule) and antisymmetric in the substrate or vice versa.

If a periodic time dependence of the charge distribution in the particle possesses the universal type of symmetry (described by eqns (9) and (10)), another symmetry constraint arises: the ratchet effect vanishes in the overdamped regime irrespective of any charge distributions in the particle and the substrate. This symmetry forbiddenness, as well as the conditions of its removal, is illustrated well by the dipole photomotors derived from strongly polarizable organic molecules. In the universalsymmetric process (i.e., with the equal durations of the states with the laser turned on and off, and pulse intensity sufficient to minimize relaxation processes), the ratchet effect becomes impossible at a specific ratio of the ground- and excitedstate dipole moments, $\mu_{1}=-3 \mu_{0}$. Nevertheless, the symmetry forbiddenness of the ratchet effect can be removed due to polarization effects, if any (provided the spatially periodic electric field in which the photomotor is placed is not (anti)symmetric). If this is the case, then the polarization contributions, no matter how small, become the predominant factor which determines the velocity and direction of photomotor motion. Although the average velocity of such polarization photomotors (about $1 \mu \mathrm{m} / \mathrm{s}$ ) is much less than that of normal dipole photomotors, it still remains in the observed range and even exceeds the characteristic velocities of typical protein motors.

The symmetry effects described here lead to the guidelines for the molecular design of dipole photomotors with desired properties. For example, in order to construct a photomotor with a stable high velocity virtually independent on external conditions, we should select compounds with a dipole moment which strongly changes in magnitude but retains its direction on excitation. On the contrary, if we aim at the fine tuning of the motor properties (velocity, direction, and stopping points) using, e.g., the polarity of the medium, we should use molecules with "symmetry instability" resulting from the specific relation between the dipole moments of the ground and excited states.

To alternatively overcome the constraints on the ratchet effect caused by the universal type of time symmetry, it is also possible to go beyond the overdamped regime by selecting sufficiently massive (i.e., inertial) particles or molecules (which should be placed in not (anti)symmetric spatially periodic electric fields).

\section{ACKNOWLEDGEMENTS}

This work was supported by the RFBR (projects 20-57-00007_Bel_a and 21-5752006_MNT_a). 


\title{
Ретчет-ефект у броунівських фотомоторах: симетрійні обмеження та їх подолання
}

\author{
М.Л. Дехтяр, В.М. Розенбаум, Н.Г. Шкода, М.І. Ікім
}

Інститут органічної хімії Начіональної академії наук України вул. Мурманська, 5, Київ,02094, Україна, mdekh@таil.ru

Інститут хімії поверхні ім. О.О. Чуйка Національної академї̈ наук Украӥни

вул. Генерала Наумова, 17, Київ, 03164, Україна, vik-roz@mail.ru

Федеральний дослідницький центр хімічної фізики ім. М.М. Семенова РАН

вул. Косигіна, 4, Москва, 119991, Російська Федерачія

\begin{abstract}
Виведено симетрійні умови виникнення ретчет-ефекту в броунівських фотомоторах. Із иією метою операції просторово-часової симетрії при векторних перетвореннях, зсувах координат і часу та в режимі надзатухання застосовувалися до середньої швидкості фотомотора, щчо розглядалася як функціонал потенціальної енергї, залежної від координати й часу. Встановлено, щุо окремі броунівські частинки (молекули) можуть рухатися спрямовано лише за умови флуктуацій у них симетрично розподіленого заряду $i$ їнього розміщення на підкладках із антисиметричним розподілом заряду, або, навпаки, вони характеризуються флуктуачіями антисиметрично розподіленого заряду і розмімуються на симетричних підкладках. Колективний спрямований рух усереднених за орієнтаціями частинок можливий лише в першому випадку. Якщз розподіл заряду частинок описується залежністю від часу з універсальним типом симетрії (тобто одночасно симетричною, антисиметричною та зсувно-симетричною), виникає додаткове симетрійне обмеження функиіонування ретчета: ретчет-ефект унеможливлюється в режимі надзатухання, але допускається для інериійних рухомих частинок, якщьо розподіл заряду як у частинці, так $i$ в підкладиі не є ані симетричним, ані антисиметричним.

Ефект універсального типу симетрії ілюструється на прикладі дипольних фотомоторів, отриманих із донорно-акцепторних супряжених органічних молекул. При особливому типі молекулярного фотозбудження та особливому співвідношенні дипольних моментів у основному та збудженому станах ретчет-ефект стає забороненим за симетрією. Заборону можна усунути за допомогою ефектів молекулярної поляризації, які в изьому випадку стають переважаючим фактором, щзо визначає напрямок руху та середню швидкість фотомоторів. Оцінені швидкості поляризачійних фотомоторів на порядок більші, ніж для відомих моторних білків $i$ дипольних броунівських фотомоторів. Ці результати можуть бути корисними у ияілеспрямованому молекулярному дизайні дипольних фотомоторів.
\end{abstract}

Ключові слова: молекулярні пристрої, ретчет-ефект у броунівських фотомоторах, обмеження за симетрією, донорно-акиепторні системи, поляризаційні ефекти

\section{REFERENCES}

1. Huxley F. Muscle structure and theories of contraction. Prog. Biophys. Biophys. Chem. 1957. 7: 255.

2. Feynman R.P., Leighton R.B., Sands M. The Feynman Lectures on Physics. (Addison-Wesley: Reading, 1963).

3. Quastel J.H. Molecular transport at cell membranes. Proc. R. Soc. 1965. B 163: 169.

4. Sauvage J.-P., Dietrich-Buchecker C. (Eds.). Molecular Catenanes, Rotaxanes and Knots: A Journey through the World of Molecular Topology. (Wiley-VCH: Weinheim, 1999).

5. Michl J., Sykes E.C.H. Molecular rotors and motors: recent advances and future challenges. ACS Nano. 2009. 3(5): 1042.

6. Deng H., Olson M.A., Stoddart J.F., Yaghi O.M. Robust dynamics. Nat. Chem. 2010. 2: 439.

7. Kudernac T., Ruangsupapichat N., Parschau M., Macia B., Katsonis N., Harutyunyan S.R., Ernst K.-H., Feringa B.L. Electrically driven directional motion of a four-wheeled molecule on a metal surface. Nature. 2011. 479: 208.

8. Peplow M. The tiniest Lego: a tale of nanoscale motors, switches and pumps. Nature. 2015. 525: 18.

9. Lau B., Kedem O., Schwabacher J., Kwasnieski D., Weiss E.A. An introduction to ratchets in chemistry and biology. Mater. Horiz. 2017. 4: 310.

10. Jülicher F., Ajdari A., Prost J. Modeling molecular motors. Rev. Mod. Phys. 1997. 69(4): 1269.

11. Astumian R.D. Thermodynamics and kinetics of a Brownian motor. Science. 1997. 276(5314): 917.

12. Reimann P. Brownian motors: Noisy transport far from equilibrium. Phys. Rep. 2002. 361(2-4): 57. 
13. Krishnan R., Mahato M.C., Jayannavar A.M. Brownian rectifiers in the presence of temporally asymmetric unbiased forces. Phys. Rev. E. 2004. 70: 021102.

14. Hänggi P., Marchesoni F. Artificial Brownian motors: Controlling transport on the nanoscale. Rev. Mod. Phys. 2009. 81: 387.

15. Cubero D., Renzoni F. Brownian Ratchets: From Statistical Physics to Bio and Nano-motors. (Cambridge: Cambridge University Press, 2016).

16. José Antonio Fornés Principles of Brownian and Molecular Motors. (Cham, Switzerland: Springer Nature Switzerland AG, 2021).

17. Dekhtyar M.L., Ishchenko A.A., Rozenbaum V.M. Photoinduced molecular transport in biological environments based on dipole moment fluctuations. J. Phys. Chem. B. 2006. 110(41): 20111.

18. Dekhtyar M.L., Rozenbaum V.M. Nonequilibrium molecular transport photoinduced by potential energy fluctuations. J. Chem. Phys. 2011. 134(4): 044136.

19. Dekhtyar M.L., Rozenbaum V.M. Symmetry interplay in Brownian photomotors: From a single-molecule device to ensemble transport. J. Chem. Phys. 2012. 137(12): 124306.

20. Rozenbaum V.M., Dekhtyar M.L., Lin S.H., Trakhtenberg L.I. Photoinduced diffusion molecular transport. J. Chem. Phys. 2016. 145(6): 064110.

21. Denisov S., Flach S., Hänggi P. Tunable transport with broken space-time symmetries. Phys. Rep. 2014. 538: 77.

22. Cubero D., Renzoni F. Hidden symmetries, instabilities, and current suppression in Brownian ratchets. Phys. Rev. Lett. 2016. 116(1): 010602.

23. Rozenbaum V.M., Shapochkina I.V., Teranishi Y., Trakhtenberg L.I. Symmetry of pulsating ratchets. JETP Lett. 2018. 107: 506.

24. Rozenbaum V.M., Shapochkina I.V., Teranishi Y., Trakhtenberg L.I. Symmetry of deterministic ratchets. Phys. Rev. E. 2019. 100(2): 022115.

25. Ikim M.I., Dekhtyar M.L., Rozenbaum V.M., Bugaev A.S., Trakhtenberg L.I. Symmetry of Brownian photomotors. Russ. J. Phys. Chem. B. 2020. 14: 332.

26. Dekhtyar M.L., Rozenbaum V.M. Symmetry rules for Brownian photomotors. MATCH Commun. Math. Comput. Chem. 2014. 71: 609.

27. Rozenbaum V.M. High-temperature Brownian motors: Deterministic and stochastic fluctuations of a periodic potential. JETP Lett. 2008. 88: 342.

28. Abe J., Shirai Y., Nemoto N., Nagase Y. Manipulation of dipole moment and hyperpolarizability based on heterocyclic pyridinium betaine structures: ab initio and INDO/S MO calculations. J. Phys. Chem. B. 1997. 101(10): 1910.

29. Pawlowska Z., Lietard A., Aloïse S., Sliwa M., Idrissi A., Poizat O., Buntinx G., Delbaere S., Perrier A., Maurel F., Jacques P., Abe J. The excited state dipole moments of betaine pyridinium investigated by an innovative solvatochromic analysis and TDDFT calculations. Phys. Chem. Chem. Phys. 2011. 13(29): 13185.

30. Dekhtyar M.L., Rozenbaum V.M., Trakhtenberg L.I. Polarization effects in organic dipole photomotors. Theor. Exp. Chem. 2019. 55: 232.

31. AMPAC 6.0 and AMPAC 6.55. (Shawnee, KS: Semichem, Inc., 1997).

32. Svoboda K., Schmidt C.F., Schnapp B.J., Block S.M. Direct observation of kinesin stepping by optical trapping interferometry. Nature. 1993. 365: 721.

33. Astumian R.D., Bier M. Fluctuation driven ratchets: Molecular motors. Phys. Rev. Lett. 1994. 72(11): 1766. 